\title{
O Ensino de Ciências na Escola do Campo: Um olhar sobre os desafios enfrentados na Escola Municipal de Ensino Fundamental Maria Luíza Balieiro Soares
}

\section{Science teaching at the field school: A look at the challenges faced at the municipal school of fundamental education Maria Luíza Balieiro Soares}

\author{
Dilsilene Baia Monteiro (dylmon2016@gmail.com) \\ (UFPA - Universidade Federal do Pará) \\ Manoel Leão Lopes Júnior (manoelleao@ufpa.br) \\ (UFPA - Universidade Federal do Pará)
}

Hellen do Socorro de Araújo Silva (hellen.ufpa@gmail.com)

(UFPA - Universidade Federal do Pará)

Lourivaldo da Silva Santos (lsslouri@gmail.com)

(UFPA - Universidade Federal do Pará)

Eder Jacson Dias Pereira (jacson.dias1@hotmail.com)

(SEMEDBAIÃO - Secretária Municipal de Educação)

Railda Neyva Moreira Araújo (raildamoreira@hotmail.com)

(SEDUCPA - Secretária Estadual de Educação do Pará)

Resumo: Esta pesquisa analisa o ensino de Ciências na turma do $9^{\circ}$ ano da escola Municipal de ensino fundamental, Maria Luíza Balieiro Soares, localizada na comunidade Tapará, no município de Oeiras do Pará. Configura-se como uma pesquisa de campo destinada a entender a concepção que os educandos possuem sobre a disciplina de Ciências e qual a importância desta para estes, questionando, também, de que forma os assuntos dessa disciplina são abordados pelo professor em sala de aula para relacionar com a perspectiva dos discentes como futuros alunos do Ensino Médio no ano de 2019. Traz-se como metodologia um estudo de caso de abordagem qualitativa, com características exploratória e técnica de coleta de dados a entrevista semiestruturada. Os resultados mostram que os alunos apresentam limitação quanto ao entendimento do ensino de ciências e a maioria mencionou que irão sentir dificuldades no Ensino Médio, pois não se sentem preparados devido a aplicação reduzida de conteúdos nos anos finais da Educação Básica. Desta forma, apresentam-se fatores que contribuem para o insucesso no processo ensino-aprendizagem, os quais são necessários discutir com a escola junto à comunidade com objetivo de estabelecer ações que contribuam de forma efetiva para a melhoria do ensino de Ciências.

Palavras-chave: Ensino de Ciências; Especificidades; Concepção; Sujeitos.

Abstract: This research aims to analyze the teaching of Science in the 9th grade class of the Municipal elementary school, Maria Luíza Balieiro Soares, located in the Tapará community, in the municipality of Oeiras do Pará. A field investigation was carried out to understand the conception that the students have about the discipline of Sciences, what is the importance of this for them, how the subjects of this discipline are approached by the teacher in the classroom to relate the perspective of students who will enter in high school in 2019. The methodology consists of a case study with exploratory 
characteristics along with the qualitative method and brings as a data collection technique semi-structured interview. The results show that the students have some limitations regarding the understanding of science teaching and most mentioned that they will face difficulties in high school, as they do not feel prepared due to the reduced application of content in the final years of Basic Education. Thus, it was found that there are factors that contribute to failure in the teaching-learning process, which are necessary to discuss with the school along with the community in order to establish actions that contribute effectively to the improvement of science education.

\section{Keywords: Science Teaching; Specificities; Conception; Subjects.}

\section{INTRODUÇÃO}

A educação é um processo constituído como um campo de conhecimento que vem se desenvolvendo ao longo do tempo. No víeis de aprendizagem são atribuídos não só fatores positivos, mas também negativos, sobretudo quando se volta o olhar à educação do campo. Percebe-se, nesse momento, que o ensino ainda é muito fragilizado.

Quando nos atentamos para o Ensino de Ciências, trazemos as observações de Fourez (2003), o qual fala em uma crise voltada para a área de ensino, enfatizando que todos são atingidos por ela, "[...] alunos, professores de ciências, pais e cidadãos". Contudo, ao olhar para a realidade das escolas rurais, cuja as marcas são a precarização, o descaso do poder público e em muitos casos isolados, trazemos uma concepção que reflete em políticas públicas paliativas inseridas na educação básica. Diante disso, compreende-se que são necessárias pesquisas sobre os desafios enfrentados por alunos do ensino fundamental na perspectiva da construção de uma escola do campo que trate a área do ensino de ciências de forma contextualizada e inter-relacionada às vivências e saberes dos sujeitos do campo.

Quando se fala dessa concepção de educação, entende-se que é através de luta, resistência e superação junto aos movimentos sociais que o povo camponês tem direitos à educação, isto gerou acesso ao conhecimento, oportunidade e transformação, logo, temos a educação como um fator indispensável para o sujeito do campo. Nisso, esta é uma modalidade da educação (Resolução n 04/2010) que passa por uma ruptura de organização e reorganização, construção e reconstrução, que é caracterizada pela existência de políticas públicas no viés dos movimentos da população do campo em 
busca de direitos garantidos, destacando-se o direito a educação de qualidade no lugar onde vivem e trabalham (ENISWELER; KLIEMANN; STRIEDER, 2012).

Entendemos o conceito de educação do campo a partir de Arroyo (2000), o qual postula que este está vinculado ao camponês, quilombolas, indígenas, ou a qualquer outro tipo de assalariado vinculado ao campo e fazem parte de um conjunto de trabalhadores que vivem nos afazeres do campo e suas atividades. Ainda Minetto (2008) salienta que "[...] a educação é responsável pela socialização, que é a possibilidade de convívio com qualidade de vida de uma pessoa na sociedade". Nessa perspectiva, tratando-se do ensino de ciências é necessário que os alunos sejam estimulados para este campo educacional, e com isso, busquem a socialização e a sua formação cidadã (FRACALANZA; AMARAL; GOUVEA, 1986).

Isso traz a discussão de que o ensino de ciências, entre outros aspectos, deve contribuir para o domínio das técnicas de leitura e escrita; permitir o aprendizado dos conceitos básicos das ciências naturais e da aplicação dos princípios aprendidos em situações práticas; possibilitar a compreensão das relações entre a ciência e a sociedade e dos mecanismos de produção e apropriação dos conhecimentos científicos e tecnológicos; garantir a transmissão e a sistematização dos saberes e da cultura regional e local, pois entendemos de maneira geral que o conhecimento da ciências está relacionado à vários contextos sociais e culturais.

Diante do exposto surge o seguinte questionamento: De que forma o curso de Licenciatura em Educação do Campo contribui na compreensão do ensino de Ciências na escola Municipal Maria Luíza Balieiro Soares? E como a formação vivenciada na Licenciatura em Educação do Campo contribuiu para a contextualização do ensino, de modo a facilitar a aprendizagem dos conteúdos pelos alunos da turma do $9^{\circ}$ ano?

Para responder a essas perguntas, esta pesquisa teve como objetivo geral analisar o ensino de Ciências na turma do $9^{\circ}$ ano na escola Municipal Maria Luíza Balieiro Soares e como a formação vivenciada na Licenciatura em Educação do Campo vem contribuindo com a contextualização do ensino de modo a facilitar a aprendizagem dos conteúdos pelos alunos e as perspectivas dos estudantes quanto ao possível ingresso no Ensino Médio no ano de 2019.

\section{METODOLOGIA}


Este trabalho de pesquisa caracteriza-se como um estudo de caso, por constituir-se como uma realidade particular e representativa, com pontos definidos que expressam referidas singularidades (SEVERINO, 2007). As fontes de informações incluíram dados da observação direta e entrevistas sistemáticas. Para tanto, o trabalho foi dividido em três etapas:

A primeira etapa, concretizou-se pela realização do estudo bibliográfico, entendo-o como aquele em que recorre às literaturas diversas, tais como: livros, artigos, revistas, dentre outros (VERGARA, 2014), para aprofundar o assunto tema deste objeto investigado, em seu aspecto teórico e prático, e com isso orientar as questões e proposições do estudo por meio das técnicas de levantamento de dados e evidências. Nesta fase, analisou-se o currículo do Ensino Fundamental, a Base Nacional Comum Curricular-BNCC (2017) e a BNC Formação, está última instituída pela Resolução $n^{0} 2$, de 20 de dezembro de 2019, que define as Diretrizes Curriculares Nacionais para a Formação Inicial de Professores para a Educação Básica e institui a Base Nacional Comum para a Formação Inicial de Professores da Educação Básica (BNC-Formação) na perspectiva de fazer uma reflexão crítica acerca do currículo apresentado por estas legislações.

$\mathrm{Na}$ segunda etapa, realizou-se a observação entendendo-a como procedimento que permite acesso aos fenômenos estudados. É a etapa imprescindível em qualquer tipo ou modalidade de pesquisa para triangular com outras fases da investigação. Está etapa ocorreu no período de um mês (novembro de 2018) na escola, com o objetivo de fazer a diagnose da relação do ensino de ciências dentro do contexto real da sala de aula na turma do $9^{\circ}$ ano do Ensino Fundamental, bem como suas vivências no cotidiano das comunidades de Arirá e Cururú.

Por fim, na terceira etapa foi realizada as entrevistas sistemáticas com seis (6) alunos na faixa etária de 14 a 18 anos para perceber o repertório próprio de conhecimentos acumulados pelos alunos quanto ao ensino de ciências e sua compreensão acerca dos conteúdos abordados. É importante destacar que estes sujeitos residem nas comunidades e vivenciam de forma cotidiana os aspectos socioculturais, produtivas e políticas de como as famílias vão se organizando no campo ribeirinho.

No contexto da realidade do campo analisado, a entrevista permitiu maiores informações em sua essência. Vale ressaltar que dos 17 alunos que formavam a turma 
do $9^{\circ}$ ano apenas 6 participaram da entrevista, isto explica-se pelos demais morarem em comunidades distantes, o que não foi possível alcançá-los pelas dificuldades de acesso às comunidades denominadas de comunidade Arirá e Cururú, por isso, o contato com esses alunos deu-se somente em sala de aula.

Os dados foram tratados de forma qualitativa e a escolha de tal abordagem de pesquisa justifica-se por trabalhar "com o universo de significados, motivos, aspirações, crenças, valores e atitudes, o que corresponde a um espaço mais profundo das relações, dos processos e dos fenômenos que não podem ser reduzidos à operacionalização de variáveis" (MINAYO, 2001, p. 22).

O lócus da pesquisa localiza-se na área rural do município de Oeiras do Pará PA, à margem esquerda do rio Anauerá, na comunidade de Tapará, cerca de $18 \mathrm{~km}$ da sede municipal, tem o rio como principal via de transporte conforme mostrado na Figura 1.

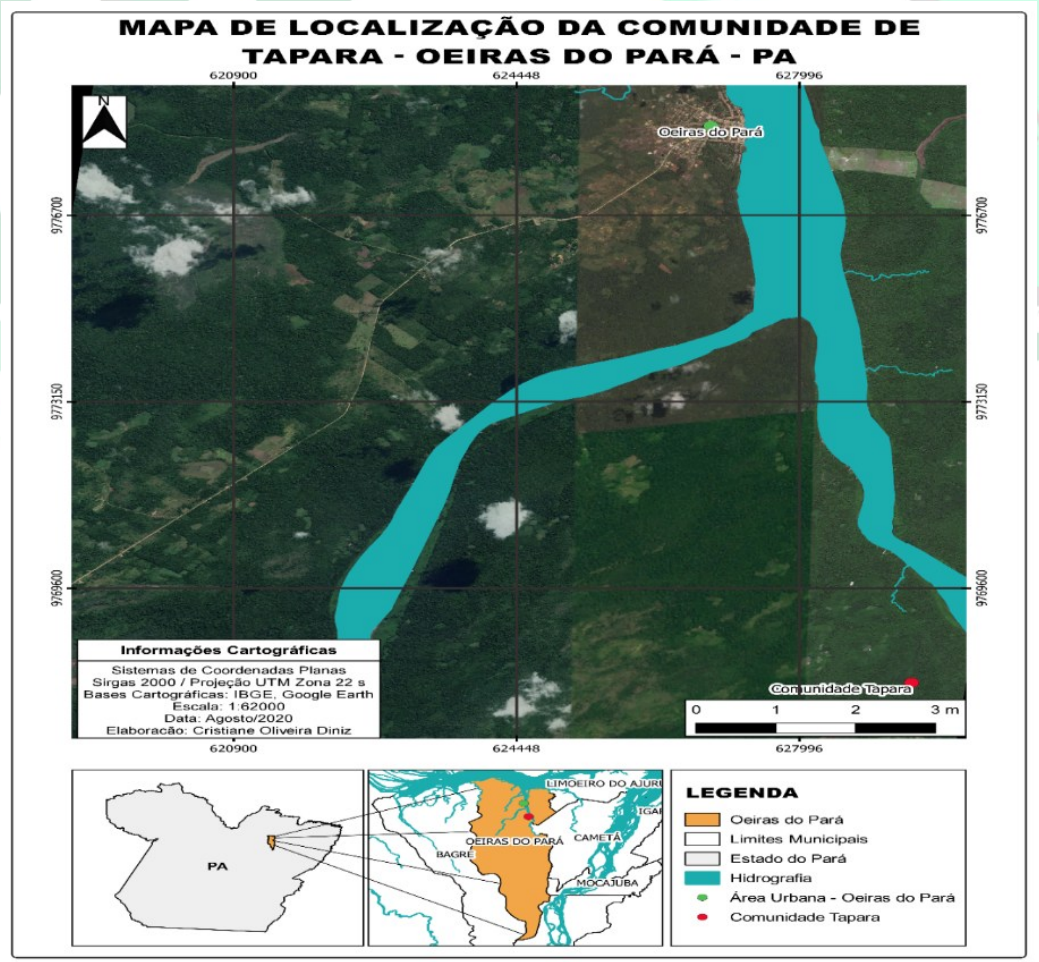

Fonte - Edir Augusto Dias Pereira

Figura 1: - Comunidade do Tapará (Oeiras do Pará, Brasil).

A Caracterização Histórica, Social e Cultural da comunidade de Tapará no ano de 2014, por intermédio do Tempo Comunidade I (tempo/espaço formativo em que o estudante da Licenciatura em Educação do Campo desenvolve suas pesquisa nos seus territórios de vivência ou de pertencimento social), foi realizada junto com o curso de 
Licenciatura em Educação da UFPA, Campus de Cametá-polo de Oeiras do Pará. A localidade investigada possui aproximadamente 349 habitantes, distribuídos em 73 famílias.

As redes de relações existentes na comunidade se dão por via de igrejas evangélicas, escola, associações de pescadores e sindicatos de trabalhadores/as rurais e através de campos de futebol masculino e feminino.

Dentre as principais atividades produtivas da comunidade de Tapará, destacam-se o cultivo da mandioca e a extração do açaí. O cultivo da mandioca, principal fonte de renda dos moradores, é permanente e realizado pela maioria dos moradores. A extração do açaí em maior escala acontece por safras, sendo que o período de maior produção geralmente ocorre entre os meses de julho a setembro.

Além do cultivo da mandioca e da extração do açaí, a renda da população da comunidade Tapará se dá também através de fontes como: aposentadoria (pessoas idosas, pensionistas e necessidades especiais), Programa Bolsa Família (contemplado pela maioria das famílias), auxilio maternidade pela Colônia de Pescadores Z-50 e Sindicato dos Trabalhadores/as Rurais, ambas as entidades estão localizadas na sede do município de Oeiras do Pará, também contam com o Seguro Defeso (pescadores associados na Colônia Z-50) e Prefeitura municipal de Oeiras-Pá (servidores públicos).

A pesquisa foi realizada na Escola Municipal de Ensino Fundamental, Maria Luíza Balieiro Soares, implantada 1988, à margem esquerda do Rio Anauerá do município de Oeiras do Pará.

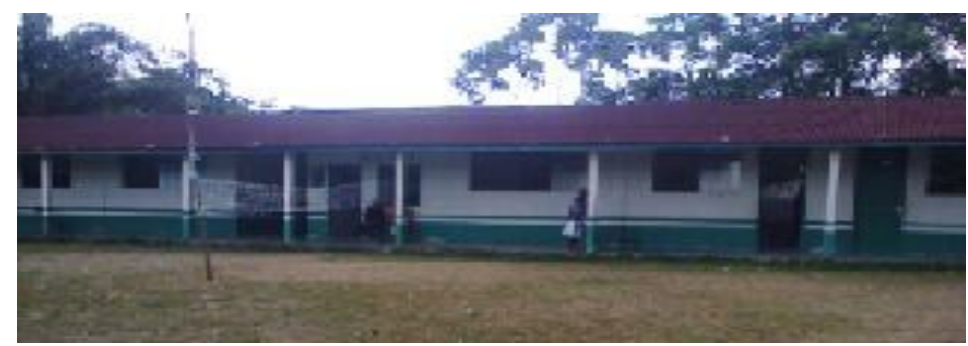

Fonte: autor 2018.

Figura 2: Escola Municipal Maria Luíza Balieiro Soares.

Durante anos, a escola funcionou em barracões e somente no ano de 2011 foi inaugurado um prédio de alvenaria possibilitando maiores suportes e visando atender a demanda de alunos locais e de comunidades vizinhas, que é o caso das comunidades do Rio Cururú e do Rio Arirá. 
Atualmente a escola conta com 04 (quatro) salas de aula padrão, 02 (dois) blocos com 03(três) banheiros adaptados ao tamanho dos alunos, uma cozinha, refeitório, além de equipamentos que dão suporte na realização das atividades administrativas e em geral (computadores, impressora, celular, antena rural, motor gerador, etc.).

A escola tem um número de 135 alunos distribuídos entre as modalidades de educação Infantil e Ensino Fundamental I e II, formando 07 turmas. Dentre estes, 17 alunos na faixa etária de 14 a 18 anos de idade cursando o $9^{\circ}$ ano. Possui um quadro de 19 funcionários, distribuído entre corpo docente, administrativo e equipe de apoio.

A escola estudada não atende o Ensino Médio, portanto, os alunos que concluem o Ensino Fundamental precisam se deslocar para a cidade de Oeiras do Pará na perspectiva de concluírem o ciclo da Educação Básica. No entanto, muitas dificuldades aparecem, entre as principais destacamos a relação com o trabalho, o que dificulta com que muitos jovens consigam dar prosseguimento em seu processo de escolarização.

\section{REFERENCIAL TEÓRICO}

\section{a. AS CIÊNCIAS DA NATUREZA NO ENSINO FUNDAMENTAL}

O ensino de Ciências da Natureza no contexto do Ensino Fundamental nas escolas do campo, situa-se no contexto das áreas de conhecimentos e do processo interdisciplinar no sentido de assumir uma posição crítica acerca da concepção de currículo apresentada pela Base Nacional Comum Curricular aprovada em 2017, visto que esta compreende currículo como um processo prescrito traduzido na listagem de descritores de conteúdos que pouco desperta o senso crítico nos educandos.

Nesse sentido, os conhecimentos socioculturais precisam se fazer presentes nas disciplinas de Química, Física e Biologia na perspectiva de possibilitar que os educandos do campo possam "compreender e intervir ainda mais sobre os fenômenos da natureza, em seus diferentes aspectos, e de mostrar qual a relação existente entre eles" (MORENO, 2014, p. 187). Sobre isso, Moreno (2014, p. 187) continua a reiterar que,

O papel fundamental do educador de ciências da natureza é criar situações de modo a deixar claro que todas as teorias que surgem não são definitivas e que elas estão sempre sendo aprimoradas com o objetivo de mostrar que a ciência é um processo que se constrói e que está em constante transformação. 
Nas escolas do campo, precisamente no ensino de ciências, é preciso garantir a perspectiva de educação ancorado com a vida no sentido de despertar nos educandos a perspectiva investigativa procurando compreender a relação homem, natureza e sociedade e como pode transformar e autotransformar-se no meio em que vive. $\mathrm{O}$ educando está na sociedade para exercer cidadania. Assim, é essencial que se conheça a ciência e seus fundamentos. Pois o estudante não é só cidadão do futuro, mas já é cidadão hoje, e, nesse sentido, conhecer ciências é ampliar a sua possibilidade presente de participação social e desenvolvimento mental, para assim viabilizar sua capacidade plena de exercício da cidadania.

De acordo com Ferraz e Terrazzan (2002) há um processo de evolução dos alunos em contato com que se aprende, ou seja, é uma relação de aprendizagem com bagagem do que se tem e se carrega no processo de ensino aprendizagem.

Angotti (1999), traz uma importante análise sobre o ensino de ciências envolvendo a tecnologia como um método atraente para a educação nas escolas brasileiras. O autor vem abordar que os conteúdos não acompanham o discurso da atualidade. Para o pesquisador, a educação brasileira fundamental atingiu efetivamente a maioria da população em tempos recentes. Contudo, temos perdido oportunidade preciosa de levar para a maioria das salas de aula um ensino mais ajustado e mais compatível com a ciência atual, sem descaracterizar ou negar suas conquistas no passado (ANGOTTI, 1999). Com base nos fundamentos dos autores citados acima, o ensino de Ciências precisa ser ensinado nas escolas de forma que possa despertar no educando o interesse pelo conhecimento, pelo criar e pelas possibilidades de compreender a si e o mundo em seu redor.

\section{b. O ENSINO dE CIÊNCIAS NA EDUCAÇÃO dO CAMPO E SUAS ESPECIFICIDADES.}

A Educação do campo é a modalidade de ensino que deve ocorrer em espaços denominados rurais nos municípios. Ela diz respeito a todo lugar de ensino situado em áreas fora do centro urbano como: matas e florestas, locais onde predominam a agricultura e a agropecuária, comunidades ribeirinhas, caiçaras, extrativistas, assentamentos indígenas e comunidades quilombolas (ROSA; ROBAINA, 2020, p. 157). 
Apesar da Educação do Campo se constituir como uma política de Estado mediante a legislação vigente (BRASIL, 2012), as questões norteadoras que visam diminuir as necessidades de professores de ciências para atuarem nas escolas do/no campo ainda faz parte de um processo histórico recente, principalmente se forem analisadas subitamente as demandas e as especificidades de Educação Rural (CALDART, 2008).

O aluno da escola campesina não pode ser visto como alguém que está somente para receber instruções, receitas, repreensões e punições, mas sim como sujeito participante, que busque construir coletivamente o saber, que vale lembrar, vai além do ato de instrução, são fatos que levam em conta as necessidades do sujeito do campo e o instrumento de luta que possibilita a transformação em sujeito de sua própria história. Segundo Saviani (1995), o conteúdo elementar da escola é ler, escrever, contar, os rudimentos das ciências naturais, das ciências sociais, da história e geografia, isto é, propicia um acesso ao saber elaborado que muitas vezes tem sido negado a realidade do campo. Caldart (2011) vem complementar que:

A identidade da escola do campo é definida pela sua vinculação às questões inerentes à sua realidade, ancorando-se na temporalidade e saberes próprios dos estudantes, na memória coletiva que sinaliza futuros, na rede de ciência e tecnologia disponível na sociedade e nos movimentos sociais em defesa de projetos que associem as soluções exigidas por essas questões à qualidade social da vida coletiva no país (CALDART, 2011).

Freire (1996) acredita em uma educação baseada no diálogo, caracterizando o educando como sujeito do processo de aprendizagem. Em sua concepção, volta-se o respeito aos saberes do aluno enfatizando que deve ser respeitado de maneira a contextualizar o ensino à vivência. Segundo o autor, discutir com os alunos a razão de ser de alguns desses saberes na relação com o ensino dos conteúdos vem no sentido de aproveitar a experiência do cotidiano dos alunos para pautar temáticas que refletem o descaso do poder público para com o campo e também com a cidade. Nesta perspectiva Freire (1996, p. 17) destaca:

Por que não discutir com os alunos a realidade concreta a que se deva associar a disciplina cujo conteúdo se ensina, a realidade agressiva em que a violência é a constante e a convivência das pessoas é muito maior com a morte do que com a vida? Por que não estabelecer uma necessária "intimidade" entre os saberes curriculares fundamentais aos alunos e a experiência social que eles têm como indivíduos? Por que não discutir as implicações políticas e ideológicas de um tal descaso dos dominantes pelas 
áreas pobres da cidade? A ética de classe embutida neste descaso? Porque, dirá um educador reacionariamente pragmático, a escola não tem nada que ver com isso. A escola não é partido. Ela tem que ensinar os conteúdos, transferi-los aos alunos. Aprendidos, estes operam por si mesmos. (FREIRE, 1996)

É pela linha de pensamento citada por Freire (1996) que se considera a Educação do Campo junto as suas especificidades para estabelecer a melhor maneira de ensino, não somente do Ensino de Ciências na qual é a temática de pesquisa, mas que esta concepção de educação se estabeleça nas escolas do campo como um todo.

\subsection{O ENSINO DE CIÊNCIAS E OS DESAFIOS NA EDUCAÇÃO DO CAMPO}

A maneira de ensinar e aprender são formas de contribuições para o enfrentamento dos desafios que se fazem necessários ao ensino de ciências na Educação do Campo. É importante refletir sobre as finalidades educativas buscando com isso compreender e analisar de forma acentuada o repertório próprio dos sujeitos imersos em situações concretas quanto o seu meio (BRITTO, 2011).

Neste sentido, considerar efetivamente os sujeitos reais do campo, e as finalidades de ensino articuladas com os princípios da Educação do Campo. Sobretudo, buscando transformações mais profundas no currículo escolar de forma a considerar as especificidades do campo como critério de escolha sobre as necessidades do que é realmente preciso constar nos programas de ensino escolares dentre o crescente corpo de conhecimento e a diversidade nas formas de fazer ciência (BRITTO, 2011).

Com base no que Caldart (2008) vem tratar, configura-se que não é de hoje que a educação vem enfrentando barreiras no seu processo de ensino, e quando se fala em Educação do Campo de qualidade, percebe-se que ainda há muito que melhorar, por isso, essa é uma questão que muito se discute, mas pouco se efetiva, isto significa que o processo de políticas públicas é lento, mas muito necessário para que de fato o ensino seja efetivado para que todos tenham direito a uma educação qualificada.

Freire (2005), fala de uma maneira de ensino em que os educandos devem ser desafiados cada vez mais, de maneira a problematizar, de um lado, a situação existencial codificada e, de outro, as próprias respostas que vão dando aqueles no decorrer do diálogo. A partir do contexto já exposto, trata-se de desafios que é possível saná-los a partir da consideração efetiva dos princípios, especificidades e demandas da Educação 
do Campo, propiciando a construção da autonomia, protagonismo e respeito às identidades do povo camponês (CALDART; 2011).

Para Sacristán e Perez (2000e 1998), os conteúdos abordados nas escolas devem ter significados para os educandos, nesta perspectiva, não se deve pensar apenas em atividades que instrumentalize conteúdos, mas que tenha significado real para o aluno. Ainda Ducatti-Silva (2005), no estudo de Ciências é imprescindível que o aluno construa e reconstrua, a partir do desempenho intelectual, seus próprios saberes, realizando importantes atribuições dessa construção em relação aos conhecimentos já existentes.

\section{RESULTADOS E DISCUSSÃO}

A pesquisa apontou que os alunos apresentam muita dificuldade em compreender o conteúdo de ciências ensinado pelo professor regente. A forma de abordagem dos conteúdos torna difícil a compreensão porque é ensinado de maneira descontextualizada, não levando em consideração a realidade dos alunos. Isto é bastante perceptível quando triangulado com a concepção do ensino de ciências colocado na BNCC (2017), pois, percebeu-se a necessidade da "contextualização histórica e social do conhecimento, das práticas investigativas e com isso a linguagem da ciência perdeu terreno [...], portanto, as mudanças constituem um currículo que é ainda mais uma "lista de conteúdos" que devem organizar a prática docente" (FRANCO; MUNFORD, 2018, p. 166).

No período das observações, identificou-se que quando o professor trabalhava sobre a água, resíduos e controle da temperatura, não buscava trazer exemplos presentes na realidade dos educandos, o que se viesse a acontecer, poderia contribuir muito para o aprendizado dos mesmos. Entretanto, a não aproximação da realidade interfere diretamente no desenvolvimento do aprendizado individual e coletivo de cada um, pois ao considerar aspectos sobre a forma de ensinar, Freire e Horton (2003) discute quão necessário é o domínio que o educador precisa ter para ensinar, havendo sempre uma relação significativa frente ao conteúdo do ensino abordado. Sobre isto, ele afirma que o ensino deve ser compreendido com aprendizado e que o professor deve ter o domino do conteúdo para que os alunos gostem de ser convidado a aprender. 
Freire e Horton (2003) dizem que o educando precisa compreender seu papel no processo de aprendiz, assumindo-se de maneira que possa se reconhecer enquanto sujeito. Ele afirma que:

O educando precisa assumir-se como tal, mas assumir-se como educando significa reconhecer-se como sujeito que é capaz de conhecer o que quer conhecer em relação com o outro sujeito igualmente capaz de conhecer, o educador e, entre os dois, possibilitando a tarefa de ambos, o objeto de conhecimento. Ensinar e aprender são assim momentos de um processo maior - o de conhecer, que implicar reconhecer (FREIRE; HORTON; 2003, p. 47).

Cabe salientar que é necessário analisar a forma de abordagem dos conteúdos, tendo em vista que dependendo do assunto, é preciso adequá-lo a uma forma de ensino que melhor transmita as informações aos alunos. Devem-se considerar ainda as necessidades e exigências da prática docente e as condições da escola e dos alunos (DELIZOICOV; ANGOTTI, 1990).

Outro ponto importante que a pesquisa apontou foi a falta de interação do professor com os alunos quanto ao conteúdo abordado, contudo, cabe comentar que a comunicação é uma ferramenta inicial para se trabalhar a Educação do Campo. A forma de se comunicar implica numa reciprocidade que não pode ser rompida. Nesse contexto, a comunicação visa à organização de participação direta do estudante em sala de aula e supõe-se que esta é a principal fonte para adquirir uma boa aprendizagem, uma vez que o aluno do campo possui cultura, potencialidade e uma pluralidade de conhecimento adquirido ao longo do tempo em suas vivências.

Assim, cabe ao educador desenvolver práticas educativas fundamentadas em concepções que visam à interação e a valorização dos diferentes educandos no campo educacional como uma prática transformadora, pois a educação se constitui como um direito de aprender, e de ampliar conhecimentos ao longo da vida não sendo uma ferramenta de escolarização.

Compreende-se que o trabalho desempenhado pelo professor vai além do simples ato de ministrar aulas, ele passa pelo processo de agir mais como um mediador do conhecimento, estabelecendo um ensino a partir das relações entre diferentes fatos, ideias, matérias de ensino, entre tópicos de aula e realidade do aluno, procurando evitar que os conteúdos de ensino se constituam por informações isoladas ou fragmentadas (KRASILCHIK; 2005). A fala de um dos estudantes revelou que: 
"A disciplina de Ciências é muito complicada, meio dificil de entender, mas às vezes até que é interessante, a gente estuda coisas sobre o nosso corpo, sobre as plantas, os animais, isso é bastante importante para nós, mas pra falar a verdade, eu não gosto muito de ciências, é uma disciplina bem chata e complicada. (Aluna A, 16 anos)".

O outro complementa:

\begin{abstract}
"acho o estudo de ciências muito bom, mas é preciso que seja analisado de uma forma que possa se tornar mais interessante no sentido de mostrar coisas da nossa realidade, aulas práticas seria uma forma de chamar mais nossa atenção e participação... (Aluno B, 16 anos)".
\end{abstract}

A disciplina de Ciências mesmo possibilitando ao educando uma visão mais crítica e reflexiva de si e do mundo ao seu redor, muitas vezes não é bem vista pelos alunos, sendo considerada chata, de difícil compreensão e para alguns até mesmo sem importância. Vigotsky (1989) destaca que a educação é ideológica e dialogante, pois dessa forma será estabelecida a verdadeira comunicação da aprendizagem entre os seres, pois numa perspectiva freiriana $\mathrm{o}$ ato de ensinar não se baseia em transferir conhecimentos, mas em criar possibilidades para a sua própria produção ou a sua construção. Neste sentido, aulas práticas seriam uma fonte eficaz para despertar o interesse dos alunos para o estudo das ciências.

Observa-se que os alunos que participam de forma direta em uma sala de aula são aqueles que se tornam sujeitos ativos de seu processo de aprendizagem, constroem e reconstroem seu próprio conhecimento, uma vez que a busca pelo novo é sempre mais intensa e mais prazerosa, mas não deixa de ser desafiadora, mas é através dos desafios que somos movidos a descobrir, a conhecer e se aproximar ainda mais do conhecimento (MOREIRA; BUCHWEITZ, 1993 e NOVAK; GOWIN, 1996).

Sobre o uso do livro didático como única ferramenta metodológica em sala de aula é uma das questões que vale discutir, mas o que é mais instigante é que o professor não abordava com os alunos os conteúdos programáticos cabíveis ao $9^{\circ}$ ano onde no viés da Base Nacional Comum Curricular do ensino fundamental o $9^{\circ}$ ano é necessário que sejam abordados estudos responsáveis pelos objetos de conhecimento que envolve aspectos quantitativos das transformações químicas, estruturas da matéria, radiações e suas aplicações na saúde, bem como vida e evolução, etc. O que se configura na fala do aluno abaixo é que: 


\begin{abstract}
"A gente estuda com o livro do $8^{\circ}$ ano, o professor fala que o livro do $9^{\circ}$ ano só tem três e não dar pra todos, então a gente estuda com o livro do $8^{\circ}$ ano que dar pra todos nós. Ele disse que lá tem muita coisa pra gente precisa aprender. O professor não ensinou muita coisa pra gente, eu não me lembro de ter estudado nada que introduzisse a Química, Física e nenhum a introdução do que é a Biologia ou a Química, por isso eu penso que vou ter muita dificuldade, mas a disciplina de Ciências é muito importante pra gente, eu gosto, mas acho que precisa ter aulas mais atrativas"(Aluno C, 15 anos).
\end{abstract}

Diante do exposto pelos entrevistados e confirmado durante o acompanhamento dos alunos em sala de aula, o livro didático, além de ser a única ferramenta utilizada pelo professor, cabe comentar que o uso do mesmo é de forma inadequada, pois o que se comprovou na pesquisa é que os alunos não estudaram os conteúdos do $9^{\circ}$ ano, o que seria a base do $1^{\circ}$ ano do Ensino Médio. Logo, percebe-se que os alunos não possuem fundamentos do que será proposto no currículo do Ensino de Ciências no Ensino Médio Regular. Isto mostra um déficit no processo de ensino e aprendizagem dos alunos do campo que pretendem ingressar no Ensino Médio.

Segundo Driver (1989, p. 481) “[...] a aprendizagem se dá através de um envolvimento ativo do aprendiz na construção do conhecimento". Entretanto, durante o acompanhamento dos alunos em sala de aula observou-se que o professor apresentava muita dificuldade em ensinar o conteúdo. Segundo os alunos entrevistados, não havia domínio de conteúdo por parte do mesmo.

Os alunos reconhecem que não se encontram totalmente preparados para atuarem no Ensino Médio. Quando instigados a refletir quanto a forma de preparação, foram convictos em suas respostas, mas o que nos foi satisfatório foi perceber que a maioria almeja conquistar, mesmo sabendo das dificuldades que enfrentarão e não estão dispostos a se limitar. Falas perseverantes, objetivas e motivadoras demostram a vontade de seguir os estudos, mesmo diante das dificuldades evidentes.

Bom, eu sei que vai ser bem difícil estudar pra Oeiras, e eu sei também que vou ter dificuldade quando for estudar Biologia, mas principalmente Química, já que percebo que é bastante complicada. Eu sei que vou ter que acordar de madrugada, vai ser chato ter que ir todo dia pra lá, ainda mais quando estiver chovendo de madrugada, mas eu quero vencer, assim como minhas irmãs venceram, eu também vou vencer. Faz parte da luta, no início vai ser complicado, mas acho que a gente acaba se acostumando com a rotina, mas eu sei que as dificuldades serão muitas, até porque é uma mudança enorme que a gente vai ter que enfrentar, mas acredito que vamos conseguir vencer, minha meta não é somente o Ensino Fundamental, eu quero dar a alegria para os meus pais, pra minha família e pra isso eu vou ter que me esforçar muito (Aluno D, 14 anos). 
O outro discente complementa:

Eu acho o ensino de Ciências muito importante, mas também desafiador. Um dia desses eu "tava" lendo um livro de Biologia, e achei bastante interessante os conteúdos, mas acho que a gente vai ter muita dificuldade no Ensino Médio, pois a gente está quase terminando o ano letivo e eu não me encontro preparado pra ir estudar em Oeiras, não somente pela questão do aprendizado, mas também pela rotina que vai ser difícil, mas eu vou dar o melhor de mim, pois eu quero avançar em meu estudo (Aluno E, 18 ANOS).

Essa questão citada pelos alunos é um desafio que os alunos do campo após concluírem o Ensino Médio, são submetidos a enfrentar, caso decidam seguir seus estudos. $\mathrm{O}$ acesso para chegar à escola é muito desgastante e as dificuldades são muitas, por isso muitos desistem e não concluem o Ensino Médio. Segundo Almeida (2009) a educação rural apresenta-se diante de muitos fatores, tais como: escolas precárias, falta de profissional, ou malformados, currículos inadequados, etc.

É importante destacar que na Escola Municipal de Ensino Fundamental Maria Luíza Balieiro Soares não existe a oferta do Ensino Médio na própria comunidade, logo para concluírem a Educação Básica, os jovens precisam fazer o deslocamento campocidade para terem acesso a está modalidade de ensino.

A realidade do município de Oeiras do Pará é apenas um demonstrativo das dificuldades que os alunos que concluem o Ensino Fundamental enfrentam para concluir seus estudos, visto que no Pará o Ensino Médio no campo é ofertado por meio do Sistema de Organização Modular de Ensino - $\mathrm{SOME}^{1}$ e no município investigado não atende $10 \%$ do número de jovens na faixa etária de 15 a 17 anos no campo (SILVA, 2017). Esse percentual revela que um número expressivo de jovens na faixa etária de 15 a 17 anos não estudam, muitas vezes, pelo fato de não terem acesso as escolas nas suas comunidades ou próximo da sua residência, como é o caso da comunidade de Tapará.

No Pará, o ensino médio nas comunidades rurais ao funcionar por meio do SOMEC ocorre em regime de colaboração entre SEDUC e Secretarias de Educação dos municípios, em 2016 atendeu 24.317 matrículas, dados de atendimento irrisório diante

\footnotetext{
${ }^{1}$ O SOME é desenvolvido através de quatro blocos de disciplinas ministradas ao longo do ano letivo, obedecendo a um esquema de revezamento composto por quatro equipes de professores, sendo que cada bloco de disciplinas corresponde a um módulo. Os módulos precisam ser trabalhados em 50 dias letivos por ano, obedecendo aos 200 dias letivos determinados conforme a LDB 9.394/96 (PARÁ, 2009, p. 18).
} 
da demanda de jovens na faixa etária de 15 a 17 anos que precisam cursar esta etapa de ensino.

Por isso, os alunos precisam se deslocar para a sede do município de Oeiras do Pará para ter direito a educação. Mas as dificuldades são inúmeras e muitos não conseguem se adaptar a rotina pesada diariamente, isto pode ser considerado como um fator primordial como causa de evasão escolar do município que reflete bastante na realidade dos jovens da comunidade, como base, temos a fala de um dos estudantes a seguir:

Sabe, eu só vou terminar o Ensino Fundamental, não vou pra Oeiras, se tivesse aqui, eu iria continuar, mas pra Oeiras não dá, eu quero trabalhar pra comprar minhas coisas e se eu for estudar pra lá não vou ter tempo pra nada, tirando a bagaceira que eu vou querer me meter, já que eu gosto de uma farra e ai que eu não vou querer saber de estudo. Tu sabes muito bem que eu prefiro trabalhar que estudar. (Aluno F, 18 anos).

Essa é uma questão que precisa ser olhada com bastante atenção, uma vez que a educação é direito de todos. Mas a ausência de políticas pública tem causado opressão a esses alunos que são impedidos de estudar em suas localidades. Segundo Freire, ${ }^{36}$ a opressão é um ato proibitivo do ser mais [...] seres humanos[...], que surge no ato de violência inaugurado pelos que têm poder.

Sabe-se que há uma grande dimensão entre sujeito do campo e sujeito urbano, e nessa dimensão a diferença na maneira de ensino, está nas práticas educativas realizada pelos professores, no convívio com o meio e com a sociedade. Pinheiro (1998) vem contribuir com esta discussão salientando que o aluno vive em situação precária, por descaso, de políticas públicas para a população do campo, e isso reflete em outras realidades sociais.

Nas escolas urbanas os alunos não são atendidos com uma educação que vise valorizar sua identidade enquanto cidadão camponês. Durante o Estágio de Docência II realizado na Escola Estadual de Ensino Médio Raimundo Ribeiro da Costa no ano de 2016, possibilitou conhecer como se configura o processo metodológico para com os alunos camponeses e nessa perspectiva, as especificidades dos alunos não estão incluídas, portanto, não valorizadas. Nesse contexto, Cerioli e Carvalho, adaptado de Alves (2009). afirmam que o povo do campo tem uma cultura própria, e este usa seus saberes de espaço, de tempo, meio ambiente diferente do mundo urbano produzindo e 
reproduzindo-se. Caldart (2008) vem complementar essa definição de forma que se devem levar em consideração a educação e suas especificidades do campo e assim analisar:

\begin{abstract}
Que mais que o direito da população ser educada no lugar onde vive, precisa ser respeitado o direito a uma educação pensada desde o seu lugar e com sua participação, vinculada a sua cultura e as suas necessidades humanas e sociais. O processo de valorização de sua cultura incentiva os sujeitos do campo a pensar e agir por si próprios, assumindo sua condição de sujeitos (CALDART; 2008).
\end{abstract}

Vale destacar que o professor que trabalha o ensino de ciências na instituição foco desta pesquisa é morador da comunidade de Tapará, atua há 18 anos no âmbito educacional e possui graduação em História e o mesmo não quis conceder entrevista. Além disso, trabalha nas séries iniciais. Contudo, cabe ressaltar que sua formação não é voltada para as Ciências da Natureza, mas sociais. Essa é uma questão que se pode levar em consideração pela falta de domínio de conteúdo e o processo metodológico quanto ao ensino de ciências trabalhado pela escola. Para Carvalho e Perez (2001)

Um dos resultados significativos provenientes das pesquisas em formação de professores é o que indica um dos obstáculos para o professor adotar uma atividade docente inovadora e criativa, além da já discutida falha no mínimo de conteúdo, são suas ideias, sobre ensino e aprendizagem (CARVALHO; PEREZ, 2001, p.111).

No entanto, foi observado que o papel do professor em sala de aula é de apenas transmitir os conteúdos gerais e tradicionais, com aulas expositivas sem utilização de práticas, limitando os conteúdos nos livros didáticos, não favorecendo o aprendizado dos alunos. Este método de ensino acaba centralizando o professor e torna os conteúdos distantes da realidade dos educandos. É consenso para os autores Krasilchik (2005), Maradino et al (2005), Sacristán (2000), Torres et al (2007) e Deelizocoiv (2000) que o conteúdo e a metodologia estão intimamente relacionados tanto para o ensino quanto para aprendizagem.

Numa abordagem de conteúdo é essencial fazer a relação do que se está sendo ensinado com a realidade dos estudantes e a pesquisa mostrou que não houve esse processo durante o acompanhamento das aulas. Segundo Oró (1999, p. 22),

Para aprender ciências naturais é necessário ter contato com a realidade para interiorizar o mundo que nos rodeia: estudar o que acontece, anotar, discutir com os companheiros ou com os professores, comparar fatos semelhantes, acompanhar um processo desde o princípio até o final” “[...] os conceitos que 
devem ser aprendidos são construídos por meio de experiências concretas estabelecidas com os objetos e os seres vivos de nosso ambiente".

Ninguém começa a entender o Ensino de Ciências sem antes aprender a ler o mundo, o que advém da capacidade de olhá-lo e interpretá-lo, e assim, defendendo a educação do campo como um exercício democrático, onde a participação, o diálogo e a construção do próprio ensino sejam baseados numa ação construtivista.

\section{CONCLUSÃO}

A pesquisa evidenciou alguns aspectos que estão presentes no dia a dia de nossas escolas campesinas, porém, pouco divulgados através de escritos acadêmicos. A primeira constatação é a de que os alunos entrevistados da escola demonstraram que alguns, apesar de gostarem de ciências e até acharem importante para suas vidas, deixaram evidentes os desafios que enfrentam para compreenderem o básico da ciência.

O segundo fator constatado na pesquisa tem influência sobre o uso do livro didático usado de maneira incorreta. Além disso, por se tratar de uma turma de $9^{\circ}$ ano e que faziam uso do livro do $8^{\circ}$ ano. O terceiro fator que podemos destacar como relevante na pesquisa está relacionado com as dificuldades que os alunos revelaram sob uma forma de não se sentirem preparados para a atuação no Ensino Médio no ano de 2019 , tendo em vista os conteúdos que não foram estudados de maneira que viesse conduzi-los de forma segura e eficiente.

Outro fator importante que a pesquisa revelou sobre o ensino de ciências na escola pesquisada foi a formação do professor que é graduado em História. Essa é uma questão que vem justificar a falta de domínio de conteúdo abordado sobre a ciência e o processo metodológico que não possui uma eficiência compensatória. Todavia, essa é uma deficiência presente na maioria das escolas do campo.

Desta forma, este trabalho vem enfatizar a relevante proposta no ensino de Ciências na Educação do/no Campo e consequentemente para a Escola Municipal Maria Luíza Balieiro Soares juntamente a comunidade de Tapará que vem contribuir como proposta de ampliar e rever a maneira de ensino que vem sendo empregado no atual sistema e desenvolvido com os alunos na instituição.

Assim, é necessário que haja compreensão de que o espaço rural brasileiro, de forma alguma é o que se veicula nos meios de comunicação e pela opinião pública 
quando se trata de campo como lugar de atraso. Deve-se compreender que este espaço não precisa se igualar aos costumes urbanos para que seja detentor de direitos humanos, culturais, sociais, políticos e econômico, mas é extremamente necessário que seus direitos sejam assegurados. Isso significa que as políticas públicas precisam ser efetivadas e executadas como parte de um processo de equidade entre sujeitos garantidos constitucionalmente.

Destarte, cabe ressaltar que o ensino de Ciências tem grande relevância no âmbito educacional, social e pessoal de cada indivíduo, quer seja ele estudante, agricultor ou pescador, o que levamos em consideração é a pessoa enquanto sujeito. Contudo, esse ser enquanto sujeito precisa está incluído na sociedade, assim, enfatizamos a valorização dos mesmos.

Por isso é necessário fazer uma reflexão diante de seus métodos, atuando como agentes de construção e transformação social. Para além disso, apresentar maneiras de intervir, desenvolver e buscar melhorias no ensino e aprendizagem através de aulas diferencias de maneira que os alunos se sintam contemplados, relacionando os assuntos com a realidade dos alunos utilizando metodologias de ensino diversificadas como a experimentação, ludicidade, tema gerador, situações problema aumentando o interesse em estudar,

\section{REFERENCIAS}

ALMEIDA, D. B. “A educação rural como processo civilizador”. In: STEPHANOU, M. B; CAMARA, M. H (orgs). Histórias e memórias da educação no Brasil. v. 3.3 ed. Petrópolis, RJ: Vozes, 2009.

ALVES, G. L. Discurso sobre educação do campo: ou como a teoria pode colocar um pouco de luz num campo muito obscuro. In ALVES, Gilberto Luiz. (org.). Educação no campo: recortes no tempo e no espaço. - Campinas, SP: Autores Associados, 2009. - (coleção educação contemporânea).

ANGOTTI, J. A. P. Ensino de Ciência e complexidade. II Encontro Nacional de Pesquisa em Educação em Ciências - II ENPEC - ATAS. Valinhos: ABRAPEC, 1999.

ARROYO, M. G. Apresentação In: CALDART, R.S. Pedagogia do Movimento SemTerra: escola é mais do que escola. Petrópolis: Vozes, 2000.

BRASIL, Ministério da Educação. Resolução CNE/CP N 2, de 20 de dezembro de 2019. Define as Diretrizes Curriculares Nacionais para a Formação Inicial de Professores para a Educação Básica e institui a Base Nacional Comum para a Formação 
Inicial de Professores da Educação Básica (BNC-Formação). Diário Oficial da União. Brasília, 2019.

BRASIL, Ministério da Educação. Base Nacional Comum Curricular (Terceira Versão). Ministério da Educação, Brasília, DF: MEC, 2017. Disponível em:

http://basenacionalcomum.mec.gov.br/images/BNCC _publicacao.pdf.

BRASIL/MEC/SECADI. Educação do campo: marcos normativos. SECADI Brasília: SECADI, 2012. 96 p.

BRASIL, Ministério da Educação. (2010). Resolução Nº 04, de 13 de julho de 2010. Define Diretrizes Curriculares Nacionais Gerais para a Educação Básica. Brasília, DF, 2010.

BRITTO, N. S. Formação de professores e professoras em Educação do Campo por área do conhecimento - Ciências da Natureza e Matemática. In: MOLINA, M. C.; SÁ, L. M. (Orgs.) Licenciaturas em Educação do Campo: registros e reflexões a partir das experiências-piloto. Belo Horizonte: Autêntica, 2011. (Coleção caminhos da Educação do Campo).

CALDART, R. S. Licenciatura em Educação do Campo e projeto formativo: qual o lugar da docência por área? In: MOLINA, M. C.; SÁ, L. M. (Orgs.) Licenciaturas em Educação do Campo: registros e reflexões a partir das experiências-piloto. Belo Horizonte: Autêntica, 2011b. (Coleção caminhos da Educação do Campo; 5).

CALDART, R. S. Sobre educação do campo. In: SANTOS, C. A. dos. (org.) Educação do campo: campo, políticas públicas, educação. Brasília, INCRA/MDA, 2008. pp. 67-86. (Série Por uma Educação do Campo, n. 7).

CARVALHO, A. M; GIL PEREZ, Daniel. O saber e o saber fazer dos professores. In: CASTRO, A. D; CARVALHO, A.M.P. (Org.). Ensinar e ensinar Didática para a escola fundamental e média. São Paulo: Pioneira - Thompson Learning, 2001. DELIZOICOV, D. e ANGOTTI, A. (1990). Metodologia do Ensino de Ciências. São Paulo: Cortez.

DELIZOICOV, D. Metodologia do Ensino de Ciências. São Paulo: Cortez. 2000.

DRIVER, R. Studens' conceptions and the leraning of sciences. International Journal on Science Education, v 11, 481-490. 1989.

DUCATTI-SILVA, K. C. A formação no curso de Pedagogia para o ensino de ciências nas séries iniciais. Dissertação (Mestrado em Educação), Universidade Estadual Paulista "Júlio de Mesquita Filho", Marília - SP. 2005.

ENISWELER, K. C; KLIEMANN, C. C. M; STRIEDER, D. M. O ensino de Ciências na Educação do Campo: uma pesquisa em dissertações e teses. Paraná. 2012, p. 763.

FERRAZ, D. F; TERRAZZAN, E. A. Construção do conhecimento e Ensino de Ciências: Papel do raciocínio analógico- Revista Educação, V 27 Nº 01, 2002. FOUREZ, G. Crise no Ensino de Ciências? Investigações em Ensino de Ciências-v. 8, 
n, 2, p. 109-123, 2003.

FRACALANZA, H.; AMARAL, I. A; GOUVEA, M. S. F. O ensino de ciências no primeiro grau. São Paulo: atual. 1986.

FRANCO, L. G; MUNFORD, D. Reflexões sobre a Base Nacional Comum

Curricular: Um olhar da área de Ciências da Natureza. Horizontes, v. 36, n. 1, p. 158-170, jan./abr. 2018. Disponível em: file://D:/Downloads/582-

Texto\%20do\%20artigo-1853-1-10-20180428.pdf

FREIRE, P. Pedagogia da Autonomia: Saberes necessários a prática pedagógica. São Paulo: Paz e Terra, 1996.

FREIRE, P. Pedagogia do Oprimido. 40a ed. Rio de Janeiro: Paz e Terra, 2005.

FREIRE, P; HORTON, M. O caminho se faz caminhando: conversas sobre educação e mudança social. 4 ed. Petropolis-RJ: Vozes, 2003.

FREIRE. P. Pedagogia da esperança. 13a ed. Rio de Janeiro: Paz e Terra, 2006.

KRASILCHIK, M. Prática de Ensino de Biologia. $4^{\mathrm{a}}$ ed. ver. e amp., $1^{\mathrm{a}}$ reimp.-São Paulo: Editora da Universidade de São Paulo, 2005.

MANZINI, E. J. A entrevista na pesquisa social. Didática. São Paulo, v. 26/27, p. 149$158,1991$.

MARANDINO, M. et al. (org). Ensino de Biologia: conhecimentos e valores em disputa. Niterói: Eduff, p. 208, 2005.

MINAYO, M. C. de S. (org). Pesquisa Social. Teoria, método e criatividade. 18 ed. Petropolis: Vozes, p.22, 2001.

MINETTO, M. F. Currículo na educação Inclusiva: entendendo esse desafio. 2 ed. Ver. Atual Ampliada. Curitiba: Ibpex, 2008.

MOREIRA, M. A; BUCHWEITZ, B. (1993). Novas estratégias de ensino e aprendizagem significativa. Os mapas conceituais e o Vê epistemológico. Lisboa. Plátano Edições Técnicas.

MORENO, Glaucia de Sousa. Reflexões sobre organização curricular em Ciências Agrárias e Naturais na educação do campo. In: SILVA, Idelma Santiago; SOUZA, Haroldo de; RIBEIRO, Nilsa Brito (Org.). Práticas contra-hegemônicas na formação de educadores: reflexões a partir do curso de Licenciatura em Educação do Campo do Sul e Sudeste do Pará. Brasília: MDA, 2014.

NOVAK, J. D.; GOWIN, D. B. (1996). Aprender a aprender. Lisboa. Plátano Edições Técnicas. Tradução para o português de Carla Valadares, do original Learning how to learn. 
ORÓ, I. Conhecimento do meio natural. In: Como trabalhar os conteúdos procedimentais em aula. Antoni Zabala (org). Porto Alegre: Artmed, 2 ed. 1999.

ROSA, M. V. F; ARNOLD, M. A. G. C. A entrevista na pesquisa qualitatitiva:mecanismo para validação dos resultados. Belo Horizonte: Autentica, 2008.

ROSA, S. S; ROBAINA, J. V. L. O Ensino de Ciências nas Escolas do Campo a partir da análise da produção acadêmica. Revista Insignare Scientia - RIS, v, 3 n. 2, mai./ago. 2020.

PINHEIRO, M. S. D. A concepção de educação do campo no cenário das políticas públicas da sociedade brasileira.

SAVIANI, D. Pedagogia Histórico Critica: primeiras aproximações. 5a ed. Campinas, SP: Autores Associados, 1995.

SACRISTAN, J. et al. Compreender e Transformar o Ensino. Trad. Ernani f. da Fonseca Rosa. São Paulo: 4ª ed. ArtMed, 2000.

SACRISTAN, J. G; PEREZ GOMEZ, A. I. Compreender e transformar o ensino. 4a ed. Porto Alegre: ArtMed, 1998.

SEVERINO, A. J; Metodologia do Trabalho Científico. Ed. 23,São Paulo: Cortez, 2007.

SILVA, Hellen do Socorro de Araújo. Política de formação de educadores do campo e a construção da contra-hegemonia via epistemologia da práxis: análise da experiência da LEDOC-UFPA-Cametá. 2017, 307 p. Tese de Doutorado em Educação. Programa de Pós-Graduação em Educação. Universidade Federal do Pará, 2017.

TORRES, P.L; IRALA, E. A. Aprendizagem Colaborativa. In TORRES Patrícia lupion (org). Algumas vias para Entretecer o Pensar e o Agir. Curitiba: SENAR-PR, 2007.

VERGARA, S. C. Projeto e relatórios de pesquisa em administração. São Paulo: Atlas Editora, 2014.

VIGOTSKY, L. S. A formação social da mente: o desenvolvimento dos processos psicológicos superiores. 3. Ed. São Paulo: Martins Fontes, 1989. 168p (Coleção Psicologia e Pedagogia, Nova Série). 